\title{
Pengaruh Jenis Pelarut Terhadap Aktivitas Antioksidan Ekstrak Daun Tenggulun (Protium javanicum Burm. F) Menggunakan Metode Maserasi
}

\section{Effect of Different Solvent on the Antioxidant Activity of Tenggulun Leaves Extract (Protium javanicum Burm.F) With the Maceration Method}

\author{
Agnes Citra Yolanda Simamora $^{1}$, Ni Luh Ari Yusasrini ${ }^{1 *}$, I Nengah Kencana Putra ${ }^{1}$ \\ Program Studi Teknologi Pangan, Fakultas Teknologi Pertanian, Universitas Udayana \\ Kampus Bukit Jimbaran, Badung-Bali \\ *Penulis korespondensi: Ni Luh Ari Yusasrini, Email: ariyusasrini@unud.ac.id
}

\begin{abstract}
This study was conducted to determine the effect of different solvents on the antioxidant activity of tenggulun leaf extract with the maceration method and to find out the right type of solvent used to extract tenggulun leaf with the highest antioxidant activity. The experimental design used in this study was a Completely Randomized Design (CRD) with various types of solvents as a treatment using maceration method. The treatment consisting of four levels, namely ethanol $90 \%$, aquades, methanol $90 \%$, and acetone $90 \%$. All treatments were repeated four times so that they were obtained 16 experimental units. The data obtained were analyzed by variance and if the treatment affected the observed variables, it was continued with the Duncan's Multiple Range Test (DMRT). The results showed that the various types of solvent treatments had a very significant effect on antioxidant activity, yields, total phenols, total flavonoids, and total tannins of tenggulun leaf extract. Methanol solvent had the best treatment which produced the highest antioxidant activity $82,36 \%$, $\mathrm{IC}_{50} 13,52 \mathrm{ppm}$, yields $7,94 \%$, total phenols $38,56 \mathrm{mg} \mathrm{GAE} / \mathrm{g}$, total flavonoids $10,75 \mathrm{mg}$ QE/g, total tannins $5,65 \mathrm{mg}$ $\mathrm{TAE} / \mathrm{g}$.
\end{abstract}

Keywords: tenggulun leaf, solvent, maceration, antioxidant activity

\section{PENDAHULUAN}

Tenggulun (Protium javanicum Burm.F) termasuk dalam family Burseraceae merupakan tanaman tinggi dengan batang yang kokoh, kuat dan berduri. Tenggulun sering dimanfaatkan sebagai obat alternative dan mempunyai khasiat yang ampuh. Daun tenggulun memiliki bentuk meruncing pada bagian ujung daun, ukuran tidak begitu lebar dan memiliki warna hijau gelap yang mengkilat pada daun yang tua. Daun tenggulun sering digunakan sebagai jamu untuk obat diare, perut nyeri, dan kurang nafsu makan. Selain itu oleh masyarakat Bali daun tenggulun digunakan sebagai obat batuk dan sakit perut dalam bentuk ekstraknya (Sossef et.al., 1998). Daun tenggulun juga dapat dimanfaatkan sebagai bumbu masakan karena memiliki aroma daun yang khas. Kekhasan dari daun tenggulun ini adalah berbau asam dan mengandung minyak yang mudah menguap (Heyne, 1987).

Komposisi kimia pada daun tenggulun meliputi minyak atsiri, triterpenoid, fenol, steroid, flavonoid, kuinon dan tanin (Bandeira et al., 1999). Senyawa bioaktif seperti flavonoid, fenol, dan tanin dapat berfungsi sebagai antioksidan karena dapat menghambat aktivitas radikal bebas dan membantu proses pertumbuhan dalam tubuh, serta mengganti sel-sel yang rusak. Pengambilan senyawa bioaktif dari suatu tanaman dapat dilakukan menggunakan metode maserasi. Maserasi merupakan metode sederhana yang paling banyak digunakan. Metode ini dilakukan 
dengan memasukkan serbuk simplisia dan pelarut yang sesuai ke dalam wadah inert yang tertutup rapat pada suhu kamar. Kelebihan dari metode maserasi adalah biayanya yang murah, mudah untuk dilakukan dan tanpa pemanasan sehingga tidak merusak senyawa flavonoid (Cuppet et al., 1954).

Salah satu faktor yang berpengaruh pada metode maserasi adalah jenis pelarut. Pemilihan jenis pelarut harus mempertimbangkan beberapa faktor antara lain selektivitas, kemampuan untuk mengekstrak, toksisitas, kemudahan untuk diuapkan dan harga pelarut (Harborne, 1987). Larutan pengekstraksi yang digunakan disesuaikan dengan kepolaran senyawa yang diinginkan. Menurut prinsip like dissolves like, suatu pelarut akan cenderung melarutkan senyawa yang mempunyai tingkat kepolaran yang sama. Pelarut polar akan melarutkan senyawa polar dan sebaliknya.

Pelarut polar yang bisa digunakan untuk ekstraksi flavonoid adalah air, etanol $90 \%$, aseton 90\%, dan metanol 90\%. Air digunakan sebagai pelarut karena bersifat polar, universal, dan mudah didapat. Menurut Kemit et al. (2016) aktivitas antioksidan tertinggi ekstrak daun alpukat diperoleh dari pelarut etanol 90\%. Sementara Suryani et al. (2015) melaporkan bahwa aktivitas antioksidan tertinggi ekstrak daun matoa diperoleh dari pelarut aseton 90\%. Selain itu Novita, (2016) melaporkan bahwa aktivitas antioksidan tertinggi ekstrak daun ubi kayu diperoleh dari pelarut metanol. Namun, belum ditemukan jenis pelarut yang tepat untuk mendapatkan aktivitas antioksidan tertinggi dari ekstrak daun tenggulun.
Oleh karena itu, dalam penelitian ini bertujuan untuk mengetahui pengaruh jenis pelarut terhadap aktivitas antioksidan ekstrak daun tenggulun menggunakan metode maserasi serta untuk mendapatkan jenis pelarut yang paling tepat dalam memperoleh ekstrak daun tenggulun dengan aktivitas antioksidan yang tinggi menggunakan metode maserasi.

\section{METODE}

\section{Tempat dan Waktu}

Penelitian ini dilaksanakan di Laboratorium Analisis Pangan dan Laboratorium Pengolahan Pangan Program Studi Teknologi Pangan Fakultas Teknologi Pertanian Universitas Udayana, Kampus Sudirman. Waktu pelaksanaan penelitian ini dilakukan pada bulan Februari sampai dengan bulan Agustus 2020.

\section{Bahan dan Alat}

Bahan yang digunakan dalam penelitian ini adalah daun tenggulun muda dengan kriteria warna berwarna hijau muda, daun muda diambil dari 3-5 tangkai di bawah pucuk. Daun tenggulun yang digunakan diperoleh dari Bukit Jimbaran. Bahan kimia yang digunakan antara lain: aquades, etanol $90 \%$, metano1 $90 \%$, aseton $90 \%$, DPPH (2,2diphenyl-1-picrylhydrazy) (Himedia), standar asam galat (Sigma-Aldrich), Folin-ciocalteu $(M E R C K)$, standar asam tanat (Sigma-Aldrich), standar kuersetin (Sigma-Aldrich), $\mathrm{AlCl}_{3}$ (MERCK), $\mathrm{Na}_{2} \mathrm{CO}_{3}$ (MERCK), metanol p.a (pro analysis), dan reagen Folin Denis (MERCK).

Alat yang digunakan dalam penelitian ini adalah rotary vacuum evaporator, pisau, timbangan analitik (Shimadzu ATY224), oven, 
blender (Cosmos), sentrifius (Danamon IEC), vortex (Maxi Mix II Type 367000, kertas saring Whatman No. 1, aluminium foil (Klin Pack), corong, gelas beaker, spektrofotometer (Genesys 10S UV -Vis), kertas label, botol gelap, gelas ukur (Pyrex), labu ukur $5 \mathrm{ml}$ (Pyrex), labu ukur $10 \mathrm{ml}$ (Pyrex), kufet kaca, spatula, ayakan 60 mesh, tabung sentrifus, tabung reaksi (Pyrex), pipet volume (Pyrex), dan pipet mikro (Socorex).

\section{Rancangan Percobaan}

Rancangan yang digunakan pada penelitian ini adalah Rancangan Acak Lengkap (RAL) dengan perlakuan jenis pelarut yang terdiri dari empat (4) taraf meliputi P1 (Pelarut etanol 90\%), P2 (Pelarut aquades), P3 (Pelarut metanol 90\%), P4 (Pelarut aseton 90\%) serta setiap perlakuan diulang sebanyak 4 kali sehingga diperoleh 16 unit percobaan.

\section{Pelaksanaan Penelitian}

\section{Pembuatan Bubuk Daun Tenggulun}

Daun tenggulun dibersihkan dengan cara dicuci hingga bersih dan ditiriskan. Selanjutnya daun tenggulun dipotong kecil-kecil dengan ukuran $3 \mathrm{~cm} \quad x \quad 3 \mathrm{~cm}$ dengan tujuan untuk mempermudah pengeringan dan penghancuran lalu dikeringkan dengan menggunakan oven pada suhu $50^{0}$ selama 24 jam. Setelah itu dihaluskan dengan menggunakan blender dan kemudian diayak menggunakan ayakan 60 mesh sehingga diperoleh bubuk daun tenggulun (Widarta dan Arnata (2017) yang dimodifikasi).

\section{Ekstraksi Bubuk Daun Tenggulun}

Daun tenggulun diekstrak menggunakan metode maserasi. Bubuk daun tenggulun yang telah diayak, masing-masing ditimbang sebanyak
10 gram lalu dilarutkan dengan variasi jenis pelarut (aquades, aseton 90\%, metanol 90\%, etanol 90\%) sebanyak $100 \mathrm{ml}$. Perbandingan bahan dengan pelarut adalah 1:10 (b/v), kemudian dimaserasi selama 30 jam pada suhu kamar dengan intensitas pengadukan setiap $5 \mathrm{jam}$. Setelah itu larutan disaring dengan kertas saring Whatman no 1. Filtrat kemudian dipekatkan menggunakan rotary vacuum evaporator pada suhu $40^{\circ} \mathrm{C}, 200 \mathrm{mBar}$ kecepatan 60rpm.. Ekstrak daun tenggulun yang diperoleh kemudian dianalisis rendemen, kadar total fenol, kadar total flavonoid, kadar total tanin, dan aktivitas antioksidannya (Widarta dan Arnata (2014) yang dimodifikasi).

\section{Parameter yang Diamati}

Parameter yang diamati dalam penelitian ini meliputi total rendemen ekstrak dengan metode pengeringan (AOAC, 1990), kadar total fenol dengan metode folin-ciocalteu (Sakanaka et al., 2003), kadar total flavonoid dengan metode spektrofotometri menggunakan reagen $\mathrm{AlCl}_{3}$ (Rohman et al., 2007), kadar total tanin dengan metode folin dennis (Suhardi, 1997), dan aktivitas antioksidan dengan metode DPPH (2,2-difenil-1pikrilhidrazil) (Molyneux, 2004).

\section{HASIL DAN PEMBAHASAN}

Nilai rata-rata rendemen, kadar total fenol, kadar total flavonoid, kadar total tanin, aktivitas antioksidan, dan $\mathrm{IC}_{50}$ dari ekstrak daun tenggulun dapat dilihat pada Tabel 1.

\section{Rendemen Ekstrak Daun Tenggulun}

Hasil sidik ragam menunjukkan bahwa jenis pelarut berpengaruh sangat nyata $(\mathrm{P}<0,01)$ terhadap rendemen ekstrak daun tenggulun. Nilai 
rata-rata total rendemen ekstrak daun tenggulun terendah diperoleh pada perlakuan menggunakan pelarut aquades (P2) yaitu 5,29\% sedangkan nilai rata-rata total rendemen tertinggi diperoleh pada ekstrak daun tenggulun dengan pelarut etanol 90\% (P1) yaitu $14,99 \%$.

Tabel 1. Nilai rata-rata rendemen, kadar total fenon, kadar total flavonoid, kadar total tanin, aktivitas antioksidan dan $\mathrm{IC}_{50}$ dari ekstrak daun tenggulun

\begin{tabular}{ccccccc}
\hline Jenis Pelarut & $\begin{array}{c}\text { Rendemen } \\
(\%)\end{array}$ & $\begin{array}{c}\text { Total Fenol } \\
(\mathrm{mg} \mathrm{GAE} / \mathrm{g})\end{array}$ & $\begin{array}{c}\text { Total } \\
\text { Flavonoid } \\
(\mathrm{mg} \text { QE/g) }\end{array}$ & $\begin{array}{c}\text { Total Tanin } \\
(\mathrm{mg} \\
\text { TAE/g) }\end{array}$ & $\begin{array}{c}\text { Aktivitas } \\
\text { Antiokisidan } \\
(\%)\end{array}$ & IC 50 (ppm) \\
\hline P1 (Etanol) & $14,99 \pm 1,08^{\mathrm{a}}$ & $31,86 \pm 0,93^{\mathrm{b}}$ & $8,62 \pm 0,37^{\mathrm{b}}$ & $6,88 \pm 0,29^{\mathrm{a}}$ & $70,84 \pm 0,44^{\mathrm{b}}$ & $19,98 \pm 0,56^{\mathrm{c}}$ \\
P2 (Aquades) & $5,29 \pm 0,56^{\mathrm{d}}$ & $10,29 \pm 1,09^{\mathrm{d}}$ & $2,30 \pm 0,12^{\mathrm{d}}$ & $2,81 \pm 0,26^{\mathrm{d}}$ & $20,29 \pm 0,12^{\mathrm{d}}$ & $262,20 \pm 5,49^{\mathrm{a}}$ \\
P3 (Metanol) & $7,94 \pm 1,78^{\mathrm{c}}$ & $38,56 \pm 0,42^{\mathrm{a}}$ & $10,75 \pm 0,31^{\mathrm{a}}$ & $5,65 \pm 0,23^{\mathrm{b}}$ & $82,36 \pm 0,12^{\mathrm{a}}$ & $13,52 \pm 0,20^{\mathrm{d}}$ \\
P4 (Aseton) & $11,70 \pm 2,08^{\mathrm{b}}$ & $17,02 \pm 0,72^{\mathrm{c}}$ & $5,37 \pm 0,23^{\mathrm{c}}$ & $3,81 \pm 0,14^{\mathrm{c}}$ & $63,21 \pm 0,40^{\mathrm{c}}$ & $82,24 \pm 2,47^{\mathrm{b}}$ \\
\hline
\end{tabular}

Keterangan: huruf yang berbeda di belakang nilai rata-rata pada setiap kolom yang sama menunjukkan perbedaan yang sangat nyata $(\mathrm{P}<0,001), \mathrm{n}=4$

Hal tersebut menunjukkan bahwa tingkat kepolaran senyawa yang terkandung pada ekstrak daun tenggulun mendekati kepolaran etanol yang memiliki konstanta dielektrik sebesar 24. Tingginya rendemen ekstrak daun tenggulun dengan menggunakan pelarut etanol menunjukkan bahwa pelarut etanol mampu mengekstrak senyawa lebih baik, karena perolehan senyawa didasari oleh kesamaan sifat kepolaran terhadap pelarut. Menurut Azis et al., (2014) pelarut etanol memiliki dua sisi yang terdiri dari gugus $\mathrm{OH}^{-}$yang bersifat polar dan gugus $\mathrm{CH}_{2} \mathrm{CH}_{3}$ yang bersifat nonpolar sehingga dapat mengekstrak senyawa aktif baik dari golongan polar maupun nonpolar. Kemit et al., (2016) yang meneliti tentang pengaruh jenis pelarut terhadap aktivitas antioksidan daun alpukat melaporkan bahwa ekstrak daun alpukat menggunakan pelarut etanol menghasilkan rendemen tertinggi dibandingkan dengan pelarut metanol, aseton dan aquades.

\section{Kadar Total Fenol Ekstrak Daun Tenggulun}

Hasil sidik ragam menunjukkan bahwa jenis pelarut berpengaruh sangat nyata $(\mathrm{P}<0,01)$ terhadap kadar total fenol ekstrak daun tenggulun. Nilai rata-rata total fenol terendah diperoleh pada perlakuan menggunakan pelarut aquades (P2) yaitu $10,29 \mathrm{mg} \mathrm{GAE} / \mathrm{g}$, sedangkan nilai rata-rata total fenol tertinggi diperoleh pada ekstrak daun tenggulun dengan pelarut metanol 90\% (P3) yaitu $38,56 \mathrm{mg} \mathrm{GAE} / \mathrm{g}$.

Hasil penelitian ini menunjukkan bahwa pelarut metanol efektif digunakan untuk mengekstrak fenol pada daun tenggulun. Tingkat kepolaran pelarut metanol menunjukkan kecocokan dengan senyawa fenol pada daun tenggulun sehingga dapat menghasilkan ekstrak dengan kadar fenol tertinggi. Metanol memiliki konstanta dielektrik sebesar 33 yang menunjukkan bahwa metanol merupakan pelarut polar. Hal ini sesuai dengan penelitian yang dilakukan oleh Savitri et al., (2017) bahwa pelarut metanol menghasilkan kadar total fenol tertinggi pada ekstrak Sargassum polycystum dengan metode maserasi dibandingkan dengan pelarut aseton dan etanol. Menurut Eskin et al., (2001), metanol merupakan pelarut yang paling baik dalam mengekstrak senyawa fenol. Kadar total fenol 
ekstrak aquades lebih rendah dibandingkan dengan total fenol ekstrak yang lain. Hal ini dikarenakan aquades merupakan senyawa yang paling polar dibandingkan pelarut lainnya, sehingga komponen yang bersifat polar seperti karbohidrat akan ikut terekstrak sehingga menyebabkan total fenol per berat sampel menjadi rendah (Septian dan Asnani, 2012).

\section{Kadar Total Flavonoid Ekstrak Daun Tenggulun}

Hasil sidik ragam menunjukkan bahwa perlakuan jenis pelarut berpengaruh sangat nyata $(\mathrm{P}<0,01)$ terhadap kadar total flavonoid ekstrak daun tenggulun. Nilai rata-rata total flavonoid terendah diperoleh pada perlakuan menggunakan pelarut aquades (P2) yaitu 2,30 $\mathrm{mg}$ QE/g, sedangkan nilai rata-rata total flavonoid tertinggi diperoleh pada ekstrak daun tenggulun dengan pelarut metanol 90\% (P3) yaitu 10,75 mg QE/g.

Hasil penelitian menunjukkan bahwa metanol efektif digunakan untuk mengekstrak flavonoid pada daun tenggulun. Tingkat kepolaran pelarut metanol menunjukkan kecocokan dengan senyawa flavonoid pada daun tenggulun sehingga dapat menghasilkan ekstrak dengan kadar flavonoid tertinggi. Metanol memiliki konstanta dielektrik sebesar 33 yang menunjukkan bahwa metanol merupakan pelarut polar. Hal ini sesuai dengan penelitian Suryani et al. (2015) bahwa pelarut metanol menghasilkan kadar total flavonoid lebih tinggi dibandingkan dengan pelarut air, aseton, dan etanol pada ekstrak daun matoa. Menurut prinsip polarisasi, suatu senyawa akan larut pada pelarut yang mempunyai kepolaran yang sama (Harborne, 1987). Rendahnya kadar flavonoid pada ekstrak dengan pelarut aquades diduga akibat banyaknya kandungan senyawa nonfenol seperti karbohidrat dan terpene dalam ekstrak aquades (Do et al., 2014).

\section{Kadar Total Tanin Ekstrak Daun Tenggulun}

Hasil sidik ragam menunjukkan bahwa jenis pelarut berpengaruh sangat nyata $(P<0,01)$ terhadap kadar total tanin ekstrak daun tenggulun. Nilai rata-rata total tanin terendah diperoleh pada perlakuan menggunakan pelarut aquades ( $\mathrm{P} 2)$ yaitu sebesar 2,81 mg TAE/g, sedangkan nilai rata-rata total tanin tertinggi diperoleh pada ekstrak daun tenggulun dengan pelarut etanol 90\% (P1) yaitu $6,88 \mathrm{mg} \mathrm{TAE} / \mathrm{g}$.

Hasil penelitian ini menunjukkan bahwa pelarut etanol efektif digunakan untuk mengekstrak tanin pada daun tenggulun. Tingkat kepolaran etanol sesuai dengan senyawa tanin pada daun tenggulun sehingga etanol dapat menghasilkan kadar total tanin yang paling tinggi dibandingkan dengan pelarut lainnya. Menurut Pandey dan Shalini (2014) etanol dapat melarutkan tanin. Lestari et al. (2014) melaporkan bahwa daun alpukat yang di ekstrak dengan metode Soxhlet menghasilkan kadar tanin tertinggi dengan pelarut etanol. Hal serupa juga dilaporkan oleh Chandran et al. (2011) bahwa pelarut etanol menghasilkan kadar total tanin tertinggi pada ekstrak eceng padi.

\section{Aktivitas Antioksidan ( IC $\left._{50}\right)$ Ekstrak Daun Tenggulun}

Hasil sidik ragam menunjukkan bahwa jenis pelarut berpengaruh sangat nyata $(\mathrm{P}<0,01)$ terhadap aktivitas antioksidan ekstrak daun 
tenggulun. Nilai rata-rata aktivitas antioksidan terendah diperoleh pada perlakuan menggunakan pelarut aquades (P2) yaitu 20,29\%, sedangkan nilai rata-rata aktivitas antioksidan tertinggi diperoleh pada ekstrak daun tenggulun dengan pelarut metanol $90 \%$ (P3) yaitu $82,36 \%$. Tingginya aktivitas antioksidan ekstrak daun tenggulun dengan pelarut metanol sejalan dengan tingginya komponen bioaktif yang terekstrak seperti fenol, flavonoid, dan tanin dengan menggunakan pelarut metanol. Shahidi dan Naczk (1995) mengemukakan bahwa senyawa yang tergolong antioksidan alami dari golongan senyawa fenolik seperti senyawa fenolik sederhana, flavonoid, dan tanin.

Hasil sidik ragam menunjukkan bahwa jenis pelarut berpengaruh sangat nyata $(P<0,01)$ terhadap $\mathrm{IC}_{50}$ ekstrak daun tenggulun. Nilai ratarata $\mathrm{IC}_{50}$ terendah diperoleh pada perlakuan menggunakan pelarut metanol 90\% (P3) yaitu 13,52 ppm, sedangkan nilai rata-rata tertinggi diperoleh pada perlakuan menggunakan pelarut aquades yaitu sebesar 262,20 ppm. Menurut Molyneux (2004) pada penelitiannya menyatakan bahwa aktivitas antioksidan diukur dari nilai $\mathrm{IC}_{50}$, yang dinyatakan nilai $\mathrm{IC}_{50}$ berbanding terbalik dengan aktivitas antioksidan. Semakin rendah nilai $\mathrm{IC}_{50}$ maka akan semakin baik aktivitas antioksidannya. Menurut Blois (1958), suatu senyawa memiliki antioksidan sangat kuat apabila nilai $\mathrm{IC}_{50}$ kurang dari $50 \mathrm{ppm}$, antioksidan kuat apabila nilai $\mathrm{IC}_{50}$ antara 50-100 ppm, antioksidan sedang apabila nilai $\mathrm{IC}_{50}$ berkisar antara 100-150 ppm dan antioksidan lemah apabila $\mathrm{IC}_{50}$ berkisar antara $150-200 \mathrm{ppm}$ dan apabila nilai $\mathrm{IC}_{50}$ diatas dari 200 ppm maka termasuk kedalam antioksidan sangat lemah. Nilai $\mathrm{IC}_{50}$ yang dimiliki oleh ekstrak daun tenggulun dengan pelarut metanol 3,52 ppm yang berarti ekstrak daun tenggulun dengan pelarut metanol tergolong dalam antioksidan sangat kuat. Nilai ini lebih rendah dibandingkan dengan nilai $\mathrm{IC}_{50}$ ekstrak daun ubi kayu yaitu 16,06 ppm dan lebih tinggi dibandingkan nilai $\mathrm{IC}_{50}$ ekstrak daun rosella yaitu $0,00044 \mathrm{ppm}$.

\section{Hubungan Antara Total Fenol, Total Flavonoid, dan Total Tanin dengan Aktivitas Antioksidan Ekstrak Daun Tenggulun}

Berdasarkan hasil penelitian, total fenol, total flavonoid, dan total tanin memiliki korelasi positif terhadap aktivitas antioksidan. Hubungan antara total fenol, total flavonoid, dan total tanin dengan aktivitas antioksidan ekstrak daun tenggulun dapat dilihat pada Gambar 1, 2, dan 3. Berdasarkan Gambar 1, 2, dan 3 koefisien korelasi $\left(\mathrm{R}^{2}\right)$ antara total fenol dengan aktivitas antioksidan ekstrak daun tenggulun yaitu 0,7776 , sementara koefisien korelasi $\left(\mathrm{R}^{2}\right)$ antara total flavonoid dengan aktivitas antioksidan ekstrak daun tenggulun yaitu 0,8767 dan koefisien korelasi $\left(\mathrm{R}^{2}\right)$ antara total tanin dengan ekstrak daun tenggulun yaitu 0,7865 .

Menurut Sarwono (2006) koefisien korelasi $\left(\mathrm{R}^{2}\right)$ yang mempunyai nilai antara 0,75 0,99 dapat dikategorikan berkorelasi sangat kuat. Semakin tinggi nilai koefisien korelasi maka semakin tinggi tingkat keeratan hubungan kedua variabel. Berdasarkan data yang diperoleh koefisien korelasi $\left(\mathrm{R}^{2}\right)$ antara total fenol, total flavonoid, dan total tanin dengan aktivitas antioksidan ekstrak daun tenggulun memiliki nilai 
di atas 0,75 sehingga dapat disimpulkan bahwa aktivitas antioksidan ekstrak daun tenggulun dipengaruhi oleh total fenol, total flavonoid, dan total tanin. Total flavonoid dan aktivitas antioksidan ekstrak daun tenggulun memiliki korelasi yang paling dekat yaitu 0,8767 . Semakin banyak senyawa flavonoid maka aktivitas antioksidan semakin meningkat. Hal ini sesuai dengan yang dilaporkan oleh Rohman et al. (2007) bahwa total flavonoid berbanding lurus dengan aktivitas antioksidan.

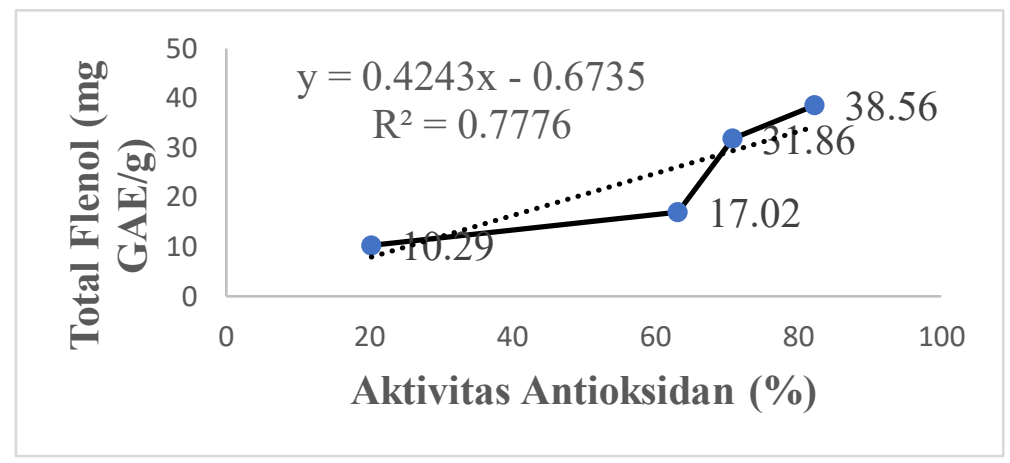

Gambar 1. Grafik hubungan antara total fenol dengan aktivitas antioksidan ekstrak daun tenggulun

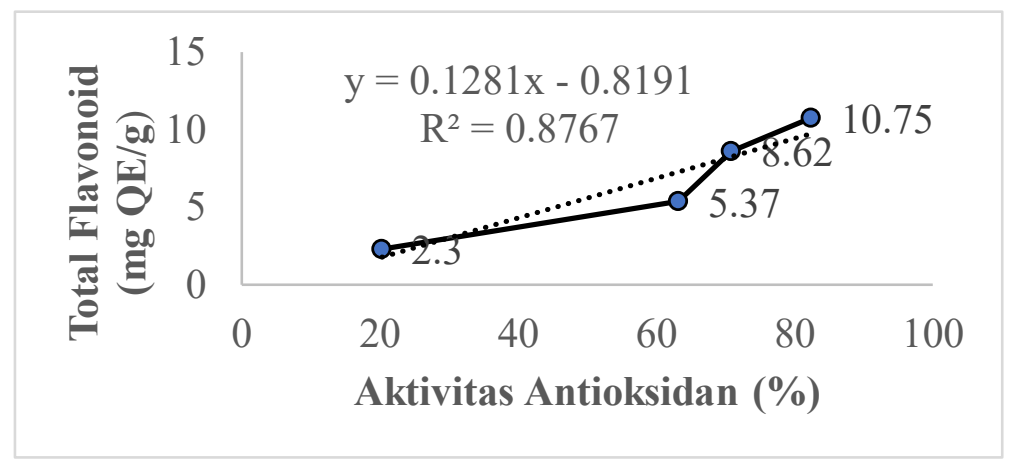

Gambar 2. Grafik hubungan antara total flavonoid dengan aktivitas antioksidan ekstrak daun tenggulun

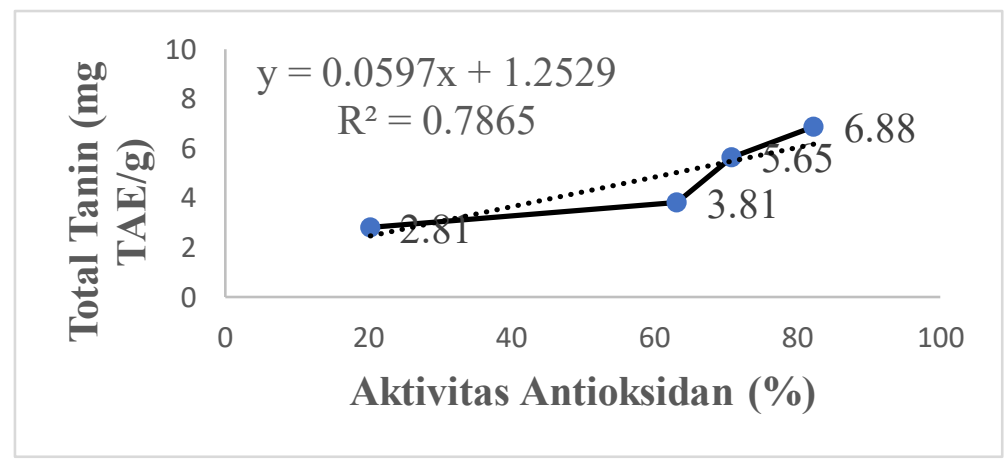

Gambar 3. Grafik hubungan antara total tanin dengan aktivitas antioksidan ekstrak daun tenggulun 


\section{KESIMPULAN DAN SARAN}

\section{Kesimpulan}

Berdasarkan hasil penelitian yang dilakukan, maka dapat disimpulkan beberapa hal sebagai berikut:

1. Jenis pelarut berpengaruh sangat nyata terhadap rendemen, total fenol, total flavonoid, total tanin, dan aktivitas antioksidan ekstrak daun tenggulun

2. Pelarut terbaik yang dapat digunakan untuk mengekstrak daun tenggulun adalah metanol 90\% yang menghasilkan aktivitas antioksidan tertinggi yaitu $82,36 \%, \quad \mathrm{IC}_{50} \quad 13,52 \mathrm{ppm}$, rendemen $7,94 \%$, kadar total fenol $38,56 \mathrm{mg}$ GAE/g, kadar total flavonoid 10,75 mg QE/g, dan kadar total tanin 5,65 mg TAE/g.

\section{Saran}

Perlu dilakukan penelitian lebih lanjut dengan menggunakan metode ekstraksi lainnya sehingga dapat diketahui metode terbaik yang dapat digunakan untuk mengekstrak daun tenggulun.

\section{UCAPAN TERIMAKASIH}

Penulis mengucapkan terima kasih kepada Fakultas Teknologi Pertanian khususnya Program Studi Teknologi Pangan dan rekan-rekan semua yang telah membantu dalam pembuatan penelitian ini.

\section{DAFTAR PUSTAKA}

AOAC. (1990). Official Method of Analysis of Association Official Agriculture Chemist. Washington DC.

Azis, T., Febrizky,S. dan Mario, A.D. (2014). Pengaruh Jenis Pelarut terhadap Persen Yield alkaloid dari Daun Salam India (Murraya koenighi). Palembang: Universitas Sriwijaya.

Bandeira, P.N., M.I.L. Machado., F.S Cavalcanti., dan T.L.G Lemos. (1999). Essential oil Composition of Leaves, Fruits and Resin of Protium heptaphyllum, Journal Essential Oil Research 48 :33-34.

Blois, M. (1958). Antioxidant determinations by the use of a stable free radical. Nature. 181:1199-1200.

Chandran, R., P. Thangaraj, S. Shanmugam, S. Thankarajan, dan A. C. Karuppusamy. (2011). Antioksidant and anti-inflammatory potential of Monochoria vaginalis (Burm. F). C. Presl. : a wild edible plant. Journal of Food Biochemistry.

Cuppett, S., M. Schrepf dan C. Hall. (1954). Natural Antioxidant - Are They Reality. Dalam Foreidoon Shahidi: Natural Antioxidants, Chemistry, Health Effect and Applications, AOCS Press, Champaign, Illinois: $12-24$

Do, Q. D., A. E. Angkawijaya, P.L. Tran-Nguyen, L.H. Huynh, F. E. Soetaredjo, dan S. Ismadji. (2014). Effect of extraction solvent on total phenol content, total flavonoid content, and antioxidant activity of Limnophila aromatica. Journal of Food and Drug Analysis 22: 296302.

Eskin, N.A.M. and R. Przybylski. (2001). Antioxidants and Shelf Life of Foods. CRC Press LLC, Florida.

Harborne, J.B. (1987). Metode Fitokimia Penuntun Cara Modern Menganalisis Tumbuhan. Penerbit ITB. Bandung.

Heyne, K. (1987). Tumbuhan Berguna Indonesia II, Edisi I, Badan Penelitian dan Pengembangan Kehutanan, Departemen Kehutanan, Jakarta.

Kemit, N., I.W.R. Widarta dan K.A. Nocianitri. (2016). Pengaruh jenis pelarut dan waktu maserasi terhadap kandungan senyawa flavonoid dan aktivitas antioksidan ekstrak daun alpukat (Persea Americana Mill). Jurnal Ilmu dan Teknologi Pangan 2(5) 130-141.

Lestari, P., S. Wijana., W.I. Putri. (2014). Ekstraksi Tanin dari Daun Alpukat (Persea Americana Mill) sebagai Pewarna Alami (Kajian Proporsi Pelarut dan Waktu Ekstraksi). Skripsi S1. Tidak dipublikasikan. Departemen Teknologi Industri Pertanian Fakultas Teknologi Pertanian Universitas Brawijaya. 
Molyneux, P. (2004). The use of stable free radical diphenyl picryl hydrazyl (dpph) for estimating antioxidant activity. Songklanakarin J. Sci. Technol; 26 (2): 211219.

Nihayah, A. (2018). Penentuan Aktivitas Antioksidan dan Antidiabetes Ekstrak Daun Tenggulun (Protium javanicum Burm.F) Secara In Vitro. Skripsi, Fakultas Farmasi, Universitas Jember, Jember.

Novita, M., M. I. Sulaiman., dan S. Yura. (2016). Pengaruh Jenis Pelarut terhadap Aktivitas Antioksidan dan Kandungan Fenol Beberapa Jenis Bayam dan Sayuran Lain. Jurnal Ilmiah Mahasiswa Pertanian Unsyiah, 1(1):935-940.

Pandey, A. dan T. Shalini. (2014). Concept of standarization, ectraction and pree phytochemical screening strategies for herbal drug. Journal of Pharmacognosy and Phytochemistry. 2(5): 115-119.

Rohman, A., S. Riyanto dan N.K. Hidayati. 2007. Aktivitas Antioksidan, Kandungan Fenolik Total, dan Flavonoid Total Daun Mengkudu (Morinda citrifolia L.). Jurnal Farmasi Universitas Gajah Mada 17(3): 136-142.

Sakanaka S., Y. Tachibana., Okada, and Yuki. (2003). Preparation and antioxiant properties of extracts of Japanese persimo leaf tea (Kakinocha-Cha). Food Chemistry. 89:569575.

Savitri, I., L, Suhendra., dan N. M. Wartini. (2017). Pengaruh Jenis Pelarut pada Metode Maserasi terhadap Karakteristik Ekstrak Sargassum polycystum. Jurnal Rekayasa dan Manajemen Agroindustri 5(3): :93-101.

Septian, A.T., dan A. Asnani. (2012). Kajian sifat fisikokimia ekstrak rumput laut coklat Sargassum duplicatum menggunakan berbagai pelarut dan metode ekstraksi. Agrointek. 6(1). 22-28.

Shaidi, F dan M. Naczk. (1995). Food Phenolics. Technomic pub.Co. Inc., Lanceser-Basel.

Sossef, M. S. M., L. T. Hong, dan P. S. (1998). PROSEA (Plants Resources of South- East Asia) No 5 (3); Timber Tress. Lesser-known timbers.

Suhardi. (1997). Analisis senyawa polifenol produk buah-buahan dan sayuran. Vol 3. Lab. Kimia-Biokimia Pengolahan Fakultas Teknologi Pertanian. Universitas Gadjah Mada. Yogyakarta.

Suryani, N.C., Permana, D.G.M. dan Jambe, A.A.G.N. (2015). Pengaruh jenis pelarut terhadap kandungan total flavonoid dan aktivitas antioksidan ekstrak daun matoa (Pometia pinnata). Jurnal Ilmu dan Teknologi Pangan 5(1):1-10.

Widarta, I W.R. dan I W. Arnata. (2014). Stabilitas aktivitas antioksidan ekstrak bekatul beras merah terhadap oksidator dan pemanasan pada berbagai $\mathrm{pH}$. Jurnal Teknologi dan Industri Pangan 25(2) : 193-199.

Widarta, I W.R. dan I W. Arnata. (2017). Ekstraksi komponen bioaktif daun alpukat dengan bantuan ultrasonik pada berbagai jenis dan konsentrasi pelarut. Jurnal Agritech. 37 (2) : 158-166.

Windyaswari A.S, Y. Karlina, A. Junita. (2018). Pengaruh Teknik dan Pelarut Ekstraksi Terhadap Aktivitas Antioksidan dari Empat Jenis Ekstrak Daun Rosella (Hibiscus sabdariffa L.). Jurnal Saintek, 1(3):014-019. 